It has been suggested that chromium compounds do not act as immunogens themselves but act by denaturing autologous protein, rendering them autoantigenic. ${ }^{23}$ This view has, however, been disputed and an alternative suggestion is that the chromium acts as a haptene and forms a conjugate with protein. ${ }^{22}$ A similar haptene-like mechanism has been suggested in the case of nickel sensitivity. ${ }^{24}$ Such an event may occur in the tissues around the prosthesis. The mechanism by means of which the cell-mediated immune response causes loosening at the prosthesis/bone interface is unknown and must be the subject of further study.

In conclusion, there is now evidence that metal-on-metal total joint replacements do sensitise the patient to metals contained in the prosthesis. Sensitisation seems to be correlated with the wear characteristics of the prosthesis, and the incidence of metal sensitivity is greatest in recipients of joints with a high wear rate. Although there is a high incidence of failure of prostheses among patients with metal sensitivity it would be premature to ascribe the former to the latter with any degree of certainty. A question which clearly needs to be resolved is whether the loosening occurs before the sensitisation to metal or whether it follows it. Further studies are in progress which we hope will resolve this problem and also throw some light on the mechanism of loosening in the presence of an immunological response.

We acknowledge the help given in the organisation of this investigation by Miss Joyce Bradley, deputy medical records officer, Royal National Orthopaedic Hospital; and Miss Jane Cotterill, who also helped with the preparation of the manuscript. We thank our colleagues on the staff of the Royal National Orthopaedic Hospital for allowing us to study patients under their care.

\section{References}

${ }^{1}$ Evans, E M, et al, Fournal of Bone and Foint Surgery, 1974, 56B, 626.

2 Scales, J T, and Lowe, B A, in Total Hip Replacement, ed M Jayson. London, Sector Publishers, 1974.

${ }^{3}$ Winter, G D, in Materials for Use in Medicine and Biology, ed D F Williams. London, Sector Publishers, 1974.

${ }^{4}$ Coleman, R F, Harrington, J, and Scales, J T, British Medical fournal, $1973,1,527$.

${ }^{5}$ McKenzie, A W, Aitken, C V, and Ridsdill-Smith R, British Medical fournal, 1967, 4, 36.

${ }^{6}$ Symeonides, P P, Paschaloglou, C, and Papegeorgiou, S, fournal of Allergy and Clinical Immunology, 1973, 51, 251.

'Barranco, V P, and Soloman, $\mathrm{H}$, Fournal of the American Medical Association, 1972, 220, 1244.

8 Pegum, J S, Lancet, 1974, 1, 674.

${ }^{9}$ Fisher, A A, Contact Dermatitis, 2nd edn. Philadelphia, Lea and Febiger, 1973.

${ }^{10}$ Fregert, S, and Rorsman, H, Acta Dermato-Venerologica, 1966, 46, 144.

${ }^{11}$ Ashman, D M, personal communication, 1975.

12 Wilson, J N, and Scales, J T, Clinical Orthopaedics, 1973, 95, 239.

${ }^{13}$ Swanson, S A V, Freeman, M A R, and Heath, J C, fournal of Bone and foint Surgery, 1973, 55B, 759.

${ }^{14}$ Gimenez-Camarosa, J M, et al, British fournal of Dermatology, 1975, $92,9$.

${ }^{15}$ MacLeod, T M, Hutchinson, F, and Raffle, E J, British fournal of Dermatology, 1970, 82, 487.

${ }^{16}$ Hutchinson, F, Raffle, E J, and MacLeod, T M, fournal of Investigative Dermatology, 1972, 58, 362.

${ }^{17}$ Pappas, A, Orfanos, C E, and Bertram, R, fournal of Investigative Dermatology, 1970, 55, 198.

${ }^{18}$ Forman, L, and Alexander, S, British fournal of Dermatology, 1972, 87, 320

19 Grosfeld, J C M, et al, Dermatologica (Basel), 1966, 132, 189.

20 Jung, E G, Therapeutisch Umschau, 1969, 26, 94.

21 Elves, M W, unpublished observation, 1975.

22 Polak, L, Turk, J L, and Frey, J R, Progress in Allergy, 1973, 17, 145.

${ }_{23}$ Pautrizel, R, Rivasseau, J, and Rivasseau-Coutant, A, Médicine et Hygiène, $1962,533,47$

${ }^{24}$ Jansen, L H, Berreus, L, and Van Delden, J, Dermatologica (Basel), 1964 128,491 .

\title{
Acute cardiomyopathy with rhabdomyolysis in chronic alcoholism
}

\author{
BASIL I B SENEVIRATNE
}

British Medical fournal, 1975, 4, 378-380

\section{Summary}

Of five chronic alcoholics with acute skeletal muscle necrosis (rhabdomyolysis) three developed acute heart failure with disturbances of rhythm and conduction. Symptoms came on abruptly after a period of intensified drinking. Myocardial infarction, thiamine deficiency, and cobalt intoxication were excluded. Probably the whole spectrum of muscle disease in chronic alcoholism may be commoner than has been suspected.

\section{Introduction}

Hed et $a l^{12}$ described an acute muscular syndrome in chronic alcoholics characterised by aching, tenderness, and oedema in the muscles and subcutaneous tissues; muscle necrosis (rhabdomyolysis); increased levels of creatinine phosphokinase

Southland Hospital, Invercargill, New Zealand BASIL I B SENEVIRATNE, MD, MRCP, physician
(CPK), serum transaminases (SGOT and SGPT), and lactate dehydrogenase (LDH); and myoglobinuria. The leg muscles were commonly affected and the clinical picture usually resembled deep vein thrombosis. All were advanced alcoholics and the symptoms occurred after a period of exceptionally heavy drinking.

Since then a spectrum of muscle disorders in alcoholism has been recognised, which ranges from no muscle symptoms but biochemical evidence of muscle disease such as a raised $\mathrm{CPK}^{3}$ to an acute reversible syndrome with muscle cramps and tenderness with no muscle necrosis, ${ }^{4}$ chronic proximal myopathy, ${ }^{3}{ }^{56}$ and acute rhabdomyolysis as reported by European workers. Except for one solitary case ${ }^{7}$ there has been no previous report of the heart being affected in the acute syndrome, and the present report on five patients with rhabdomyloysis, three of whom had unequivocal evidence of acute cardiomyopathy, extends the spectrum.

\section{Case 1}

A man aged 44 had drunk 41 of beer a day for years. After a period of exceptionally heavy drinking he presented in October 1974 with dyspnoea, palpitations, and severe pains in the upper arms, calves, and lumbar region for two days and of acute onset. He had had intermittent painful cramps in the calves and thighs for three months.

On examination he was found to be afebrile, orthopnoeic, and extremely distressed by pain in the upper arms, thighs, and lumbar 
region. Heart rate was $160 / \mathrm{min}$. The heart was clinically and radiologically enlarged, with gallop rhythm (S3) and signs of left ventricular failure. No murmurs or evidence of pericardial effusion were detected. Electrocardiography (ECG) showed paroxysmal atrial tachycardia with block and left axis deviation (fig 1). (Six months previously his heart had been normal.) The upper arm muscles, lumbar region, thighs, and calves were exquisitely tender. There was pitting oedema around the ankles. The skin over the affected muscles showed cyanotic mottling interspersed with blotchy red areas. The feet felt cool and the muscles firm and indurated. Power could not be accurately assessed owing to pain but the arms and legs appeared to be weak. There was rapid wasting of the affected muscles, the triceps virtually disappearing in the first 24 hours. He remained weak and unable to sit up or turn in bed and was tube-fed for the first week. There was no abnormality in the cranial nerves, the tendon jerks were normal, and sensation was intact.

Investigations were: haemoglobin $17.9 \mathrm{~g} / \mathrm{dl}$; ESR $1 \mathrm{~mm}$ in the first hour; WBC 16.5 $\times 10^{\%} / 1$; SGOT $550 \mathrm{U}$ (normal 8-40 U); SGPT $175 \mathrm{U}$ (normal 8-40 U); LDH $440 \mathrm{U}$ (normal 200-680 U); and CPK $205 \mathrm{U}$ (normal 0-50 U). Urine myoglobin was present. Electromyography (EMG) showed low-voltage, polyphasic potentials of short-duration consistent with a myopathic lesion. Nerve conduction, both motor and sensory, was normal. Biopsy of the triceps and gastrocnemius showed varying degrees of necrosis (rhabdomyolysis).

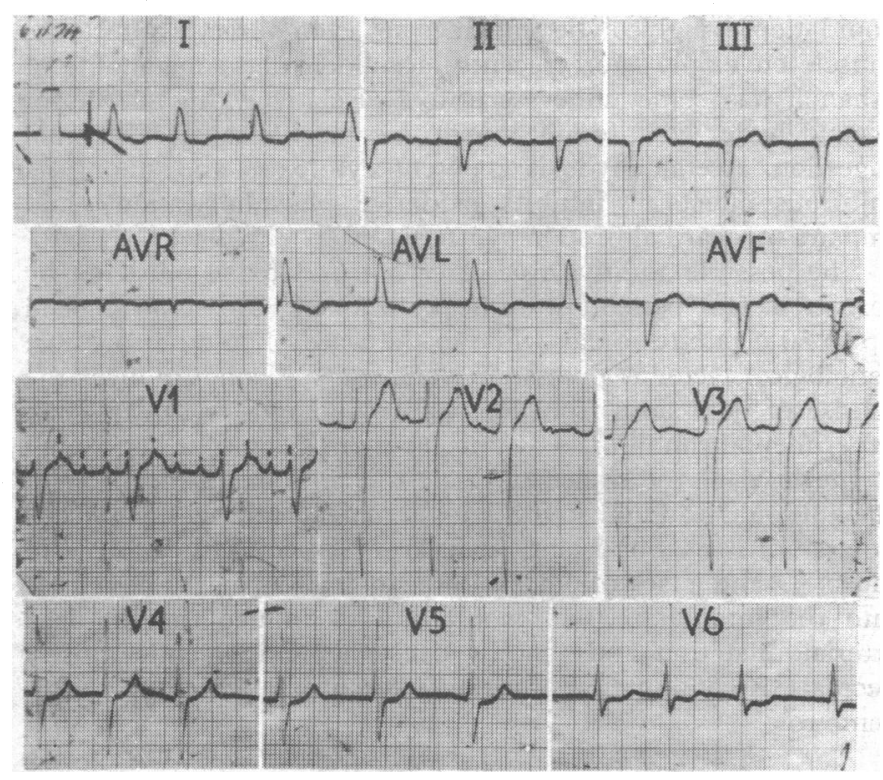

FIG 1-Case 1. ECG a few days after admission showing persistent atrial tachycardia with block and left anterior hemi-block.

\section{TREATMENT AND PROGRESS}

Heart-As there was no response to parenteral thiamine he was digitalised. He remained in paroxysmal atrial tachycardia with left anterior hemi-block till successful cardioversion with a $30-W$ second shock six weeks after admission. Improvement was gradual and serial measurements of systolic time intervals for assessing left ventricular function $^{8}$ (pre-ejection period/left ventricle ejection time; PEP/ LVET) gave the following results. Acute phase (October 1974), PEP/LVET 0.70 (normal 0.34); November, PEP/LVET 0.60; December PEP/LVET 0.58.

Skeletal muscle-Power returned gradually till after about two months he was able to walk unaided.

He abstained after being discharged and six months after the acute episode started light work as a storeman in a tyre factory, his former job, and by June 1975 was working full-time. In June his heart was still enlarged, S3 gallop was heard, and PEP/LVET was 0.50. ECG showed sinus rhythm with grade 1 block and left anterior hemi-block. Skeletal muscle power seemed to be normal.

\section{Case 2}

A man aged 53 had drunk 61 of beer and smoked 40-60 cigarettes a day for 30 years. He was first admitted in December 1973 having developed sudden painful swelling of both calf muscles after a heavy binge. Muscle biopsy showed severe rhabdomyolysis. He recovered spontaneously in three weeks. Eight months later he was readmitted with a recurrence of the symptoms in his calf muscles and dysphagia due to pharyngeal muscle dysfunction. These symptoms cleared in about six weeks and on neither occasion was there evidence of heart disease. He continued to drink and in June 1975 was admitted after a syncopal attack. There had been no chest pain. ECG showed atrial tachycardia at a rate of $140 / \mathrm{min}$. Next day he was in sinus rhythm but had developed right bundle-branch block with left axis deviation. There was evidence of left ventricular failure with S3 gallop and his symptoms improved with frusemide and digoxin. There was wasting of his shoulder girdle and proximal leg muscles. One month later these muscles were still weak and tender and the heart showed moderate cardiomegaly with S3 gallop. He appeared to have entered the phase of chronic proximal myopathy. The CPK remained high right through his illness and four weeks after discharge was still over $250 \mathrm{U}$.

\section{Case 3}

A 37-year-old man drank over 61 of beer and smoked 40-60 cigarettes a day. He was admitted because of shortness of breath for three days, weakness of limbs, and dark urine. He was confused, had horizontal nystagmus, and his muscle symptoms were similar to those in case 1. Clinically and radiologically he was in left ventricular failure with a low-output state. ECG showed grade 1 atrioventricular block. He went through a phase of delirium tremens and his heart failure gradually cleared with digitalis and diuretics. There was no response to thiamine and his blood lactate and pyruvate levels were normal. PEP/LVET was 0.60 on admission and 0.45 at discharge two months later. Muscle biopsy showed focal areas of necrosis with regeneration. EMG showed features consistent with a myopathic lesion.

\section{Case 4}

This man, aged 56, had drunk 61 of beer and smoked 40-60 cigarettes a day for many years. He first presented in June 1974 with sudden pain and swelling in the left foot followed by painful swelling of the left calf. For five weeks he had had pain in both calves suggestive of intermittent claudication. A provisional diagnosis of gout, deep vein thrombosis, and arterial insufficiency was made. All the symptoms cleared spontaneously. He continued to drink heavily and three months later was admitted with a recurrence of painful swelling in both calves, left thigh, and right upper limb muscles. His cardiovascular system was clinically normal. The ankle systolic blood pressure on both sides was above the brachial systolic pressure, thereby exlcuding peripheral vascular disease. CPK was 184 U. ECG, chest $x$-ray examination, and lower limb venography showed nothing abnormal. Muscle biopsy showed patchy areas of necrosis. EMG showed features consistent with a myopathic lesion.

\section{Case 5}

A man aged 35 who usually drank 61 of beer and smoked 40 cigarettes a day presented with painful swelling of his right thigh and left calf for two weeks after a period of exceptionally heavy drinking. There were no cardiac symptoms. In view of the mottled cyanosis, as observed in the previous cases, a provisional diagnosis of dermatomyositis was made. The correct diagnosis became apparent later. CPK was $385 \mathrm{U}$. Chest $x$-ray picture, ECG, and skin biopsy were normal. Muscle biopsy showed patchy necrosis (fig 2). EMG findings were consistent with myopathy. He made an uneventful recovery and decided to abstain. A year later he had no muscle symptoms and his left ventricular function was normal (PEP/LVET 0.31).

\section{Discussion}

The acute muscle syndrome with rhabdomyolysis classically presents as sudden pain and swelling, commonly in the leg muscle groups, in a chronic alcoholic after a period of intensified drinking. He may have had warning symptoms such as muscle cramps, symptoms resembling intermittent claudication, and 


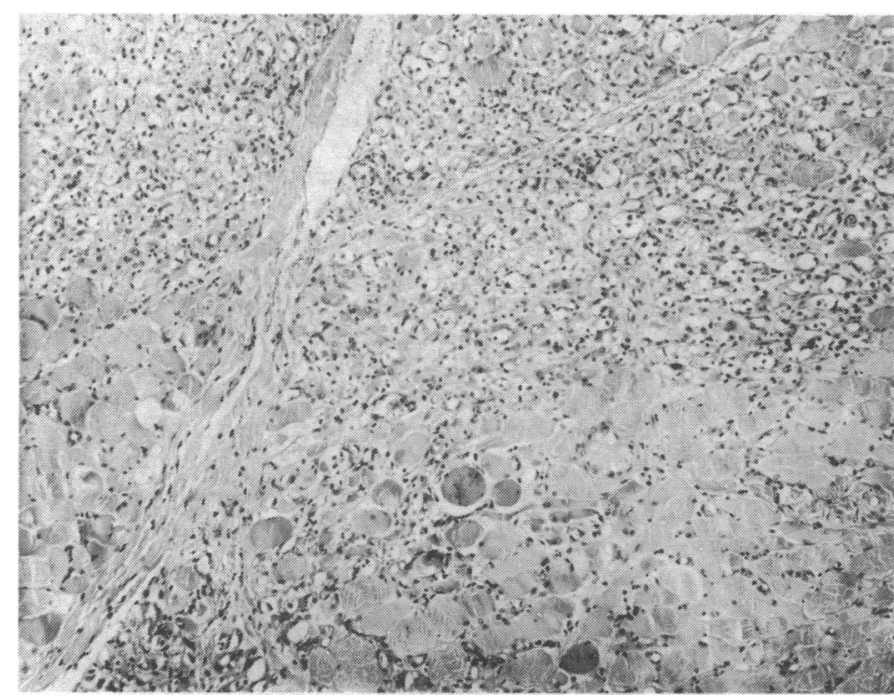

FIG 2-Case 5. Transverse section of gastrocnemius muscle biopsy specimen showing patchy rhabdomyloysis with swelling and vacuolation of sarcoplams and infiltration with macrophages. $(\mathrm{H}$ and $\mathrm{E}$. $\times 86$.) Under higher power, muscle fibre regeneration was prominent.

dark urine. The skin over the affected muscles may have a violaceous mottling, and the skin over the ankles and small joints of the feet may be red although cool to touch. There is often pitting oedema, and the underlying muscle is tender and indurated. The disease may affect one muscle group or be more widespread and affect lumbar, upper limb, pharyngeal, and heart muscle. There is often myoglobinuria with a risk of renal failure. Rapid muscle wasting and weakness follow but gradual spontaneous recovery is the rule. Although once recognised this picture is characteristic, cases may be mistaken for deep vein thrombosis of the legs, acute gout, peripheral neuritis, arterial insufficiency, dermatomyositis and polymyositis, myocardial infarction, and primary liver or gall-bladder disease. The non-specific initial symptoms, the tendency to spontaneous recovery, and the well-known difficulty of identifying the chronic alcoholic make early diagnosis difficult. Once suspected a CPK estimation should pave the way for a firm diagnosis by muscle biopsy. Having seen four cases in 18 months my impression is that the problem may be far commoner than has been suspected in most Western societies, where excessive alcohol consumption has been the regrettable price of affluence and increased leisure.

Except for one solitary case ${ }^{7}$ acute cardiac dysfunction has not been described previously in alcoholic skeletal myopathy. Perkoff et $a l^{4}$ surmised from evidence available that alcohol could have similar effects on both tissues. Cobalt added to beer to improve the stability of the "head" caused acute congestive heart failure characterised by polycythaemia and pericardial effusions. ${ }^{9}$ The addition of cobalt has since been banned, and the high haemoglobin levels seen in some of our patients could be related to heavy cigarette smoking. Deficiency of vitamin $B_{1}$, which produces hyperkinetic heart failure, was excluded by the hypokinetic low-output state, normal pyruvate levels, and lack of a dramatic response usually expected from vitamin $B_{1}$ administration. Moreover, neither cobalt nor vitamin $B_{1}$ deficiency has ever led to skeletal muscle necrosis. The acute deleterious effects of alcohol on myocardial function in man have been well described under experimental conditions. ${ }^{10} \mathrm{With}$ prolonged administration of alcohol to both man and animals deleterious effects on conduction, rhythm, function, and structure were recorded. Function could be restored after withdrawal of alcohol. The onset of acute congestive heart failure after gross alcohol abuse in persons with a previously normal heart, rhythm disturbances of atrial tachycardia with block (case 1), conduction defects such as grade 1 atrioventricular block with left anterior hemi-block (case 1), left anterior hemiblock with right bundle-branch block (case 2), all in the absence of myocardial infarction, and the gradual return of function after alcohol withdrawal (cases 1 and 3) may represent the clinical counterpart of the experimental observations. The conduction defects seem to be permanent, and, interestingly, Erlenborn and Pilz's ${ }^{7}$ patient also developed permanent right bundle-branch block.

Although the direct role of alcohol in the genesis of the cardiac and skeletal muscle injury seems irrefutable, the exact pathogenesis remains obscure. In many conditions acute muscle necrosis seems to be related to failure of energy production and possible depletion of adenosine triphosphate (ATP) necessary to maintain the integrity of sarcolemma. ${ }^{11}$ In muscle lacking phosphorylase or phosphofructokinase it is assumed that ATP decreases with exercise owing to the block of anaerobic glycolysis. Perkoff et $a l^{4}$ demonstrated the lack of phosphorylase in some, though not all, of their cases and drew a parallel with the McArdle syndrome, where the presenting symptoms are muscle pain and cramps on exercise, swelling of muscles, and myoglobinuria. They postulated that ethanol or its metabolites could depress glycolytic enzymes or even directly affect the muscle envelope. More recently acetaldehyde, a metabolite of ethanol, has come under scrutiny. ${ }^{12}$ Relatively high levels of acetaldehyde were found in chronic alcoholics after ethanol ingestion. Acetaldehyde is a potent cytotoxin, and among its injurious effects it inhibits oxidative phosphorylation ${ }^{13}$ and impairs myocardial protein synthesis. ${ }^{14}$

The possible additive role of carbon monoxide must not be forgotten. Our patients were heavy smokers, and some smoked up to 50 cigarettes a day while in the ward. The other possible aetiological factor is potassium deficiency. Alcohol induces the release of potassium from left ventrivular muscle under acute experimental conditions. ${ }^{10}$ Conceivably this could be happening at the level of the skeletal muscle too. Prolonged ingestion of alcohol could lead to absolute potassium deficiency within muscle. Potassium is an important mediator of exercise hyperaemia in muscle, ${ }^{15}$ and a lack of potassium or interference with its release into the interstitial fluid would fail to induce the required arterial dilatation and thereby cause acute ischaemic muscle necrosis. A combination of these factors probably have a pathogenic role.

I am indebted to Dr W I Paterson, medical superintendent-in-chief, Southland Hospital Board, for permission to make this report; to Dr C H Baird and Dr J O'Hagan for referring cases; to Dr O A Peiris for electromyographic studies; and to the pathologists for biopsy reports. Special thanks are due to Mrs L Hutton for secretarial help.

\section{References}

${ }^{1}$ Hed, R, Larsson, H, and Wahlgren, F, Acta Medica Scandinavica, 1955, $152,459$.

2 Hed, R, et al, Acta Medica Scandinavica, 1962, 171, 585

3 Perkoff, G T, et al, Annals of Internal Medicine, 1967, 67, 481.

4 Perkoff, G. T, Hardy, P, and Velez-Garcia, E, New England fournal of Medicine, 1966, 274, 1277.

${ }^{5}$ Ekbom, K, et al, Archives of Neurology, 1964, 10, 449

${ }^{6}$ Serratrice, G, Toga, M, and Roux, H, Presse Médicale, 1966, 74, 1721.

7 Erlenborn, J W, and Pilz, C G, Fournal of the American Medical Association, 1962, 181, 95.

8 Garrad, C L, Weissler, A M, and Dodge, H T, Circulation, 1970, 42, 455.

- Morin, Y, Canadian Medical Association Fournal, 1967, 97, 901.

${ }^{10}$ Regan, T J, Circulation, 1971, 44, 957.

11 Rowland, L P, and Penn, A S, Medical Clinics of North America, 1972 56123.

12 Korsten, M A, et al, New England fournal of Medicine, 1975, 292386.

13 Cederbaum, A L, Lieber, C S, and Rubin, E, Archives of Biochemistry and Biophysics, 1974, 16126.

14 Schreiber, S S, et al, fournal of Clinical Investigation, 1972, 51, 2820.

15 Knochel, J P, New England fournal of Medicine, 1972, 287, 927. 